\title{
Obstetric Emergencies, the Avertible Price for Giving Life to Another: A Study in Hajiya Gambo Sawaba General Hospital, Zaria.
}

Abdullahi Haruna Ibrahim¹, Amina Ahmad², Auwalu Muhammed ${ }^{3 *}$, Aisha Udoye Musa-Maliki², Hauwau Sallau Dandutse $^{2}$

${ }^{1}$ Department of Nursing Sciences, Bayero University Kano

${ }^{2}$ Department of Nursing Sciences, Ahmadu Bello University, Zaria

${ }^{3}$ Department of Nursing Sciences, Usmanu Danfodiyo University Sokoto

\begin{abstract}
Article History
Received: 18.09 .2020

Accepted: 09.10 .2020

Published: 26.12 .2020

Journal homepage:

https://www.easpublisher.com

Abstract: Aim: The study was conducted to examine the prevalence of obstetric emergencies as seen at Hajiya Gambo Sawaba General Hospital Kofar Gayan Zaria between January 2018 and June 2019. Methods: A retrospective research design was adopted for the study, data were collected from case records of 573 clients seen in the facility over the study period using a structured checklist, and the data were analysed using descriptive and inferential statistical methods. Results: The finding revealed that postpartum haemorrhage was the most leading obstetric emergency complication $(24.7 \%)$ followed closely by eclampsia and ante-partum haemorrhage with $23.7 \%$ and $20 \%$, respectively; age, parity were found to have significant association with obstetric emergencies $(\mathrm{p}<0.05)$. Discussion: Postpartum, haemorrhage was the major obstetric complication. The public and private actors should roll out of new family welfare programmes and fund them adequately to increase the women's uptake of maternal and child health services across various economic strata of the society.
\end{abstract}

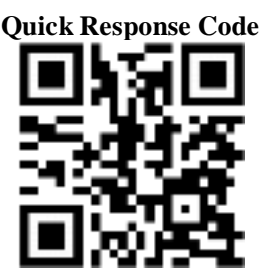

Keywords: Obstetric; Emergency; Post-partum; Haemorrhages; Eclampsia; Parity.

Copyright (C) 2020 The Author(s): This is an open-access article distributed under the terms of the Creative Commons Attribution 4.0 International License (CC BY-NC 4.0) which permits unrestricted use, distribution, and reproduction in any medium for non-commercial use provided the original author and source are credited.

\section{INTRODUCTION}

According to the World Health Organization (WHO) in 2015, in order to reduce maternal mortality, emergency obstetric care (EMOC) must be available and accessible to all women [1]. Additionally, there is a need to increase access to reproductive health care, especially, skilled birth attendance in order to reduce maternal and newborn morbidity and mortality. This came a few years after the WHO in 2012 [19] lamented that Poor obstetric outcome in middle and low-income countries like Nigeria with the attendant problems of maternal mortality remains a depressing and challenging health concern worldwide.

Nigeria, considered Africa's most populous country with a population close to 200 million is also the country where nearly $20 \%$ of all global maternal deaths happen; between 2005 and 2015 [2]. It was estimated that over 600000 maternal deaths and no less than 900000 maternal near-miss cases occurred in the country and in 2015, Nigeria's estimated maternal mortality ratio was over $800 / 100000$ live births, with approximately 58000 maternal deaths during that year and it was posited that a Nigerian woman has a 1 in 22 lifetime risk of dying during pregnancy, childbirth or postpartum/post-abortion periods compared to most developed countries, where lifetime risk stands at 1 in 4900 on average [2].

Obstetric emergencies are the leading causes of maternal mortality worldwide and particularly in developing countries where literacy, poverty, lack of antenatal care, poor transport facilities and inadequate equipment combine to magnify the problem [3]. SubSaharan Africa accounted for $66 \%$ of 303,000 women who died worldwide in 2015 from preventable causes related to pregnancy and childbirth [4]. Within subSaharan Africa, nearly $29 \%$ of the maternal deaths occurred in Nigeria with an estimated 58,000 pregnant women dying annually in the country mainly from preventable obstetric causes with many socio-economic and cultural factors been put forward to explain the high rates of maternal deaths in the country [4]. According to the Centre for Disease Control (CDC) [5], implicated in the ugly trend is inadequate obstetric care service, especially at the primary health care level.

Every pregnant woman should have access to health facilities that provide emergency care [6]. Prenatal care or identifying risk may not reduce 
maternal mortality, unless emergency obstetric care is available, accessible, and utilised [7]. Evidence indicates that access to skilled birth attendant at delivery and timely referral service to emergency obstetric care service can reduce maternal mortality and morbidity [8].

The United Nations estimated that $15 \%$ of pregnant women develop obstetric complications that require emergency care [9]. Meaning, out of the total deliveries at least $15 \%$ women should attend health facilities for emergency obstetric care services and according to Gambo and Salihu [10], the high prevalence of maternal illnesses and other potentially devastating obstetric complications suffered by women in Nigeria are generally linked to poor access to emergency obstetric care services.

Abubakar and Abdulrahman [11], in another study reported that obstetric emergencies are the leading causes of maternal mortality ratio in Nigeria and they implicated spontaneous abortion, haemorrhage, anaemia, obstructed labour, eclampsia as leading causes. Furthermore, in a WHO [1] analysis, postpartum hemorrhage was the leading cause of maternal deaths $(20.55 \%)$, followed by eclampsia (15.38\%). Among indirect causes, anemia was common, and the pattern closely resembles a study in India. It was reported that hemorrhage $(38 \%)$ as the major cause of death-toll, followed by sepsis (11\%), hypertensive disorders (5\%), and obstructed labor (5\%); the higher hemorrhage percentage is also consistent with high background rates of anemia reported among Indian women [12].

According to a recent report by Nigeria Demographic Health Survey (NDHS) [9] cited by the Gambo and Salihu [10], maternal mortality continues to be a serious problem in Nigeria with poor emergency obstetric care services in facilities. The factors contributing to the problem include health system, socioeconomic factors (poverty), poor emergency obstetric services, and fatalistic beliefs leading to postpartum haemorrhage, hypertensive disorders, unsafe abortions, and prolonged labour. Consequently, the problems have led to a high maternal mortality ratio in Nigeria, threatening Nigeria's potential of meeting SDG 3.1 target of reducing the maternal mortality ratio to less than 70 per 100,000 live births by 2030 [11].

This study was to investigate the prevalence of obstetric emergencies and associated factors as seen in Hajia Gambo Sawaba General Hospital (HGSGH). Presently, as there are currently no recent studies appraising the phenomenon in the facility. However, and another study conducted within the same metropolis by the Gambo and Saihu [10] at Ahmadu Bello University Teaching Hospital (ABUTH) revealed a prevalence of $71.27 \%$, with postpartum haemorrhage as the leading cause $(16.48 \%)$ and $2.2 \%$ of the general patient population died in the course of management. Considering HGSGH a secondary facility located within the heart of the ancient city (Zaria) receiving virtually all referrals from the many primary health facilities around Zaria, the researchers feel that, the facility may likely handle more obstetric emergencies compared to ABUTH. ABUTH is a tertiary health facility that receives advanced cases referred from the secondary tier facilities.

\section{METHODS}

This study adopted a retrospective research design to investigate the prevalence of obstetric emergencies and associated factors among patients seen at Hajiya Gambo Sawaba General Hospital, Zaria, from January 2018 to June 2019. As earlier described, Hajiya Gambo Sawaba General Hospital is a secondary level health facility in the heart of the ancient city (Zaria). Most primary health facilities in Zaria refer cases to this hospital for proper management.

The target population for this study was all the patients diagnosed as having an obstetric emergency from January 2018 to June 2019 at Hajiya Gambo Sawaba General Hospital, Zaria. The total enumerative sampling technique was used for the study. The medical/health records of all 573 patients, diagnose of obstetric emergency were used for the study.

A structured checklist was used to extract and summarize data through content analysis of the medical and health records of all the patients diagnosed as having obstetric emergency from January 2018 to June 2019 at Hajiya Gambo Sawaba General Hospital Zaria. The background information extracted from the patients' records includes age, parity, and booking status of the patients. The obstetric information obtain from each client's record (within the period of the study) includes antepartum hemorrhage, postpartum hemorrhage, eclampsia, pre-eclampsia, placenta previa, intrauterine foetal death, abortion, retained placenta, uterine rupture, obstructed labour, and puerperal sepsis.

Data was analyzed using frequency and percentage. However, a Chi-square test of independence was used to examine the association between patients' age, parity, and prevalence of obstetric emergencies.

The management of Hajiya Gambo Sawaba General Hospital, Zaria granted Clearance and permission for the conduct of this study. The primary investigator explained the purpose and requirements of the study and that all information retrieved will be handled with anonymity and confidentiality.

\section{ReSUlts}

Results in Table 1 show that the highest proportion of cases presented with obstetric emergencies was between the ages of 26-35years with 
Table-1: Socio-demographic Characteristics of the Respondents N=573

\begin{tabular}{|c|l|l|}
\hline Variables & F & \% \\
\hline Age & & \\
\hline i. 16-25 year & 176 & 30.19 \\
\hline ii. 26-35 year & 206 & 35.95 \\
\hline iii. 36 year above & 191 & 33.3 \\
\hline Total & $\mathbf{5 7 3}$ & $\mathbf{1 0 0}$ \\
\hline Parity & & \\
\hline iv. Primi-para & 160 & 27.92 \\
\hline v. Multiparous & 234 & 40.83 \\
\hline vi. Grand multiparous & 175 & 30.54 \\
\hline Total & $\mathbf{5 7 3}$ & $\mathbf{1 0 0}$ \\
\hline Antenatal & & \\
\hline vii. Booked & 235 & 44.51 \\
\hline viii. Unbooked & 318 & 55.49 \\
\hline Total & $\mathbf{5 7 3}$ & $\mathbf{1 0 0}$ \\
\hline
\end{tabular}

As illustrated in Table 2 postpartum haemorrhage is the most common obstetric emergency seen in the facility over the study period (24.7\%) followed by eclampsia $(23.9 \%)$ and antepartum haemorrhage $(20.7 \%)$, uterine rupture was the least reported obstetric emergency $(1.0 \%)$.

Table-2: Obstetric Emergencies in Hajiya Gambo Sawaba General Hospital from January 2018 to June 2019 $(\mathrm{N}=573)$

\begin{tabular}{|l|l|l|l|l|}
\hline Obstetric Emergencies & Jan-Dec 2018 & Jan-June 2019 & Total & Percentage (\%) \\
\hline Antepartum haemorrhage & 64 & 55 & 119 & $\mathbf{2 0 . 7}$ \\
\hline Postpartum haemorrhage & 119 & 23 & 142 & $\mathbf{2 4 . 7}$ \\
\hline Eclampsia & 85 & 52 & 137 & $\mathbf{2 3 . 9}$ \\
\hline Pre-eclampsia & 40 & 33 & 73 & 12.7 \\
\hline Placenta previa & 7 & 2 & 9 & 1.6 \\
\hline Intrauterine foetal death & 23 & 2 & 25 & 4.4 \\
\hline Abortion & 10 & 7 & 17 & 3.0 \\
\hline Retained placenta & 11 & 0 & 11 & 1.9 \\
\hline Uterine rupture & 5 & 1 & 6 & 1.0 \\
\hline Obstructed labour & 7 & 5 & 12 & 2.1 \\
\hline Sepsis & 11 & 11 & 22 & 3.8 \\
\hline Total & $\mathbf{3 8 2}$ & $\mathbf{1 9 1}$ & $\mathbf{5 7 3}$ & $\mathbf{1 0 0 . 0}$ \\
\hline
\end{tabular}

Findings on the relationship between the demography and obstetric emergencies in Table 3, revealed a significant relationship between age, parity and having an obstetric emergency with values of 4.398 and $6.976(\mathrm{df} 2)$ at the 0.05 level of significance respectively.

Table-3: Relationship between age, parity and obstetric emergencies in Hajiya Gambo Sawaba General Hospital from January 2018 to June 2019

\begin{tabular}{|l|l|l|l|}
\hline Variable & $\mathbf{D f}$ & $\mathbf{X}^{\mathbf{2}}$ & Sig \\
\hline Age & 2 & 4.398 & 0.034 \\
\hline Parity & 2 & 6.976 & 0.000 \\
\hline
\end{tabular}

\section{DISCUSSION}

Findings from the study showed that postpartum haemorrhage (PPH) was the leading obstetric emergency complication $(24.7 \%$,) which when compared to what was reported by Gambo and
Salihu [10] from a study at Ahmadu Bello University Teaching Hospital (ABUTH) who also found PPH as the leading emergency, the findings in this study are higher than the $16.8 \%$ reported previously. The findings are also in agreement with several other studies from different parts of the world that reported PPH as the leading obstetric emergency. However, the proportion of patients seen with the obstetric complication differs across the studies. For instance, the $24.7 \%$ found in this study is lower than the result found in Bangalore, India [13]. Catherlin et al. [13] identified PPH as most common obstetric emergency with $51 \%$ and also another study conducted by Tsu [14] and WHO (2015) who reported post-partum haemorrhage as leading obstetric emergency accounting for $28.6 \%$ and $20.55 \%$ of cases respectively followed by antepartum haemorrhage $(\mathrm{APH})$, and obstructed labour. Eclampsia was the second leading obstetric emergency in HGSGH $(23.9 \%)$ which is consistent with what was reported by Prasand et al. [12], but the prevalence $(15.38 \%)$ is 
slightly lower than what was found in this study. In addition, the $11 \%$ reported in Prasand et al. [12] for sepsis is about 10 times higher than what was found in the present study.

The study further revealed a significant relationship between age and having an obstetric emergency, which did not agree with the submission of Ann, Usha, Rajesh \& Prabhat [15]. The previous authors found that obstetric emergency was associated with the age group 20 to 30 years while Okeke [16] identified age ranges 36-40 years and 31-35 year as more vulnerable to the obstetric emergencies. However, none of the studies associated parity with having an obstetric emergency.

Furthermore, the study also found a significant relationship between parity and having an obstetric emergency. The finding corroborates with other studies from different parts of the globe. For instance, a study comparing obstetric complications among two parity groups (primiparity and multiparity) in India revealed that primiparity had a higher tendency to have obstetric complications (pregnancy induced hypertension, preterm labour, haemorrhage, foetal distress, oligohydramnios, eclampsia and the rate of emergency) compared to the multigravida [17]. In the same study, caesarean section, the number of low birth weight babies was also higher among the primiparity [17]. The authors concluded that rate of obstetric complications was higher in primiparous as compared to multiparous mothers. Mgaya et al. [18] in a study conducted in Dar Es Salaam Tanzania reported that grand multiparous had more than twice the likelihood of having obstetric emergencies (odds ratio (OR), 2.9; 95\% confidence interval (CI), 1.5-5.0) compared to the primiparous women. Although the findings of Mgaya et al. [18, 20] contradict that of Kaur and Kaur [17], both studies support the present findings that parity has a significant relationship with having an obstetric emergency.

\section{Conclusion}

The present study found haemorrhages (postpartum and antepartum haemorrhages) and eclampsia as the leading obstetric emergencies in HGSGH and that there was a significant relationship between age, parity and having an obstetric emergency among women attending the facility. The obstetric emergency has a profound effect on the mother, which can cause high maternal and foetal morbidity and mortality. One of the foremost goals of modern obstetric is to prevent complications and to ensure a healthy childbirth.

Based on the findings of the study, the public and private actors should roll out of new family welfare programmes and fund them adequately to increase the uptake maternal and child health services by women across various economic strata of the society. In addition, the antenatal care, facility delivery and postnatal care should be incentivized to motivate expectant mothers into coming for services.

\section{REFERENCE}

1. World Health Organization. (2015). Trends in Maternal Mortality: 1990 to 2015. Estimates by WHOM, UNICEF, UNFPA, the World Bank and the United Nations Population Division. Geneva, Switzerland: World Health Organization; 2015. Retrieved from: www.who.int/mediacenter/

2. World Health Organization. (2019). Recommendations for the prevention and treatment of postpartum haemorrhage. World Health Organization, Geneva.

3. Adelaja, L., \& Oladapo, O.T. (2012). Maternal and Fetal Outcome of Obstetric Emergencies in a Tertiary Health Institution in South-Western Nigeria. JOSR, $1(1), \quad 160932$. http://dx.doi.org/10.5402/2011/160932

4. World Health Organization. (2017). WHO report on the global tobacco epidemic, 2017: monitoring tobacco use and prevention policies. World Health Organization.

5. Centre for Disease Ccontrol. (2012). "Maternal and Reproductive Health Issues. Retrieved from: www.cdc.org/reproductivehealth/index.htm

6. World Health Organization. (2013). WHO recommendations for the prevention and treatment of pre-eclampsia and eclampsia. Geneva, Switzerland: World Health Organization World Health.

7. Bhandari. (2015). Reducing high mortality and child mortality remain challenges for most developing world. Kathamandu university medical journal, 1454, 94-95.

8. Kongnyuy, P. (2015). Motivation and Changing Fortunes in Teachers' Output: Empirical Evidence from Selected Secondary Schools in North West Region of Cameroon. Journal of Education and Practice, 6(5), 111-118.

9. United Nations Population Funds (UNFPA). (2016). World Bank Group and the United Nations Population Division. Geneva: World Health Organization.

10. Gambo, S.H., \& Salihu Z. (2017). Administration of Emergency Obstetric Care Services, Prevalence and Outcome in Nigeria: A Policy Dimension. FUDMA Economic and Development Review, 1(1), 79-94.

11. Abubakar, U., \& Abdurrahman, A. (2018). An Assessment of Public Health Economy in Katsina State. Health Economic Outcome Research 4,160.

12. Prasad, D., Nishat, H., Tiwary, B., Swet, N., Sinha, A., \& Goel, N. (2018). Review of obstetrical emergencies and fetal out come in a tertiary care centre. International Journal of Research in Medical Sciences, 6, 1554-8.

13. Catherin, N., Anushila S.R., \& Ramakrishna, G.B. (2014). Obstetric emergencies presenting to a rural 
community maternity hospital, Southern Karnataka, India. IJCRAR, 2(9), 264-269.

14. Tsu, A. (2015). Appropriate technology to prevent maternal mortality: current research requirements. International Journal of Obstetrics and Gynaecology, 112(9), 1213-1218.

15. Ann, L.M., Usha, R., Rajesh, K., \& Prabhat, J. (2014). Maternal mortality in India: Causes and health care service use based on a nationally representative survey. PLOS ONE, 9(1), e83331

16. Okeke, C. I. (2014). Effective home-school partnership: Some strategies to help strengthen parental involvement. South African Journal of Education, 34(3).

17. Kaur, A., \& Kaur, A. (2012). Comparison of mamdani-type and sugeno-type fuzzy inference systems for air conditioning system. International Journal of Soft Computing and Engineering (IJSCE), 2(2), 323-325.

18. Mgaya, A. H., Massawe, S. N., Kidanto, H. L., \& Mgaya, H. N. (2013). Grand multiparity: is it still a risk in pregnancy? BMC pregnancy and childbirth, 13(1), 241.

19. World Health Organization. (2012). Fact Sheet. WHO Publications. Retrieved from: www.who.int/mediacenter/factsheets/fs348/en/inde xhtm.

20. World Health Organization. (2017). Managing complications in pregnancy and childbirth: a guide for midwives and doctors. Retrived from: www.who.int/maternal-child.../managingcomplications-pregnancy-childbirth/en/ 